\title{
3,4-Dihydroxyphenylglycol Measurement
}

National Cancer Institute

\section{Source}

National Cancer Institute. 3,4-Dihydroxyphenylgyycol Measurement. NCI Thesaurus.

Code C101017.

The determination of the amount of 3,4-Dihydroxyphenylglycol present in a sample. 